\title{
TRANSFORMATION PROPENSITY IN LOW INCOME HOUSING: THE CONTINUING STORY OF THE VASTUHARA IN DHAKA
}

\author{
K. Taufiq Elahi* \\ Md. Shahidul Ameen**
}

\begin{abstract}
Dhaka, the nation's capital, has a diverse range of extremities in its general socio-economic composition. For the last few decades, the imprints of such a distinctive but composite juxtaposition have become evident through the physical and cultural bearings of its housing industry. In a broader spectrum, the overall housing divide can be identified under two opposing categories - the formal and the informal sectors. With the government agencies out of the scene as the key provider in the housing stock, the formal sector is primarily dependent on numerous real-estate organizations and private entrepreneurs. The informal sector, on the other hand, is left to survive on its own - in conditions beyond human justification, but growing steadily to meet the demands of its urban machinery and economic whirlpool. This paper reveals the tale of the Vastuhara resettlement scheme for the urban poor that stand out as a bright and optimistic example in transformative propensity where some catalectic efforts by the government and its associated donor agencies have turned out to be a spontaneous phenomenon of social and economical advancement. Various sections of this text will portray a timescape of almost 40 years or so, assessing and addressing to various architectural details, which acted as the contributing factors in its overall process of development.
\end{abstract}

Keywords: Transformation, low income housing, urban poor, vastuhara resettlement scheme, user-behavior phenomena.

\section{INTRODUCTION}

Housing, in its qualitative and quantitative terms, is perhaps the only denominator that elucidates a society and its cultural bearing with reference to its physical existence. Generally considered as a condition that provides with habitable shelter, housing situations in a city must ensure the inhabitants' right to the opportunity of living in proper houses in accordance to their equitable standings (Beyer, 1965; Rahman, 2008). In Dhaka, the continuing deterioration of conditions in appropriate services and its resulting demand-supply paradox only signifies the government's institutional and organizational incapacity to ensure universal access to this basic need (Islam, 1996 and 1998; Banks, 2008). In present circumstances, it is highly improbable that equitable distribution of resources could be achievable among its general mass. The higher and higher-middle income groups have the highest accessibility to the resources available for affordable housing expenditure; whereas, the middle and lower income groups are gradually falling out from the supply chain.

For the last few decades, formulation and execution of housing stock for the low income strata within the perimeters of Dhaka city have been suffering severely from the overwhelming lack in relevant data and technical knowhow. In-depth studies and surveys were carried out in several instances, but inconsistencies due to rapid and incessant inmigration and the city's present state of constant reformation have prevented any development initiative that was devised for the wellbeing of the urban poor (Elahi, 2005). Although there are suggestive implications for appropriate and workable directives in the first draft of the National Housing Policy (1993) and its revised proposals, the schemes were never implemented (NHA, 1993, amended: 2004 and 2010; Islam, 2005).

Projects were initiated to accommodate the urban poor within or on the fringe areas of Dhaka city. These initiatives were confirmed to be inadequate in terms of control or effective changes that they ought to bring about for the target group. Core housing at Mirpur and Mohammadpur areas during the 1950s and the 1960s, the Slum Improvement Program (SIP) funded by the World Bank, and various efforts by the UNDP, UNCHS and the ADB in the recent decades are evident testimonies to the fact where higher housing standards encouraged the upper income groups to get hold of the provisions instead and the poor eventually moved back to the inner areas of the city that are nearer to their workplace (Ameen, 1992; UNDP-UNCHS, 1993; ADB-GoB, 1993;

* K. Taufiq Elahi, Assistant Professor, Department of Architecture, Shahjalal University of Science and Technology (SUST), Sylhet, Bangladesh. ** Md. Shahidul Ameen, Professor, Department of Architecture, Bangladesh University of Engineering and Technology (BUET), Dhaka, Bangladesh. 
ADB-GoB-LGED, 1996). Vastuhara resettlement scheme, in the context of the above, demonstrates of an optimistic outcome that displays marked advancement in socioeconomic circumstances within the lowest income generating class. The dwellers' active / responsive / participation in the overall process of development, together with little or almost no intervention from the government bodies, have given birth to an example for the developing scenarios of the world where the supply of housing stock for the disadvantaged are noticeably scarce.

Transformation, in its rudimentary form (in Mirpur, Dhaka), was identified and revealed for the first time during the late80 s through the doctoral research of the co-author. ${ }^{1}$ It was subsequently followed by an ODA research scheme showing a cross-country comparison in an international level. After a few years of silence, further observations were made through small scaled fieldworks in sites under similar consideration. On the basis of these findings, a wide-ranging story of the Vastuhara resettlement scheme is attempted to be communicated in this paper.

The article not only addresses to the situations of change through time, but also investigates into various spatial and physical dimensions and their corresponding set of relationships that might have helped as the defining parameters in the overall transformative process. In doing so, the aim of this study is to identify some workable parameters, upon which guidelines can be formulated regarding low income housing in the context of Dhaka city and circumstances similar to this.

\section{VASTUHARA RESETTLEMENT SCHEME - THE BACKGROUND, THE ORIGINAL PROVISIONS}

Bangladesh had a tremendous undertaking of recovering from the economical, strategic and intellectual vacuum during her seminal years of independence. Adding up to the burden, approximately one-eighth of the total population in the city were illegally occupying several isolated pockets, abandoned railway lines and pedestrian walkways beside major arteries in the form of informal settlements. These post-war drifters were commonly named as the 'Vastuhara' (or the shelterless) by the authorities. State being the provider in the housing industry, some 27,000 units were planned during 1972-1973 by the Ministry of Relief and Rehabilitation, and consequently executed through the agencies of the Housing and Settlement Directorate (HSD) in 1973. Among the 27,000; a total number of 4,304 units under the capacity of sites and service scheme were distributed among the low-income strata of the society in different peripheral locations of Dhaka (HSD, 1979; Ameen, 1992). The project was implemented in Sections 4, 7 and 9 at Mirpur.

\subsection{The Original Provision}

During 1974-1975, an approximate total of 175,000 economically disadvantaged were uprooted from various slums and squatter settlements in Dhaka. The government could only accommodate a handful through the capacity of its Vastuhara resettlement scheme. Of 4,304 units built, the actual provision of a single tin-shed unit with only one living area per household was modified in 1,124 cases, where two were merged/combined to form one unit comprising of two rooms. These double-roomed units (562, in total) were allotted to class III and IV government employees, while distribution of the other 3,180 units remained uncertain for a good while (Ameen, 1987 and 1992; Tipple and Ameen, 1999).

The original provisions in the Vastuhara resettlement scheme included a piece of land per household without having any outline demarcating its boundary. The units usually consisted of only one habitable room (17'-11"X8'-9") that had small openings on three sides for natural illumination and ventilation. The blind side goes with the common wall between the two adjacent units in closely spaced grids. With a verandah (8'-9"X6'-2") placed on the rear as an indirect access for each house, the total built area covered an average of 247.50 sq.ft. or 23 sq.m. (Figure-1). The entrance to the dwelling units was through a door adjoining the verandah. The scheme was originally planned in a semi-detached format and the units were joined in pairs along their elongated edges, placed at a repetitive organization. The alternate rows left narrow but open-to-sky passages between two pairs. The brick-built walls were laid on single pile, while the floors had crude net-finishing. Each pair of units formed a double-pitch ceiling, having corrugated iron (CI) sheets as overhead coverings.

Provisions for lavatories were placed separately - roughly between every sixth dwelling - with a number of latrine blocks that were fitted with pits and pans. The lavatories

1 Ameen M.S., 1987; Housing for the Lower Income People of Dhaka, Bangladesh: A peri-Urban Development Approach (unpublished Ph.D. dissertation); University of Newcastle upon Tyne, Newcastle. 

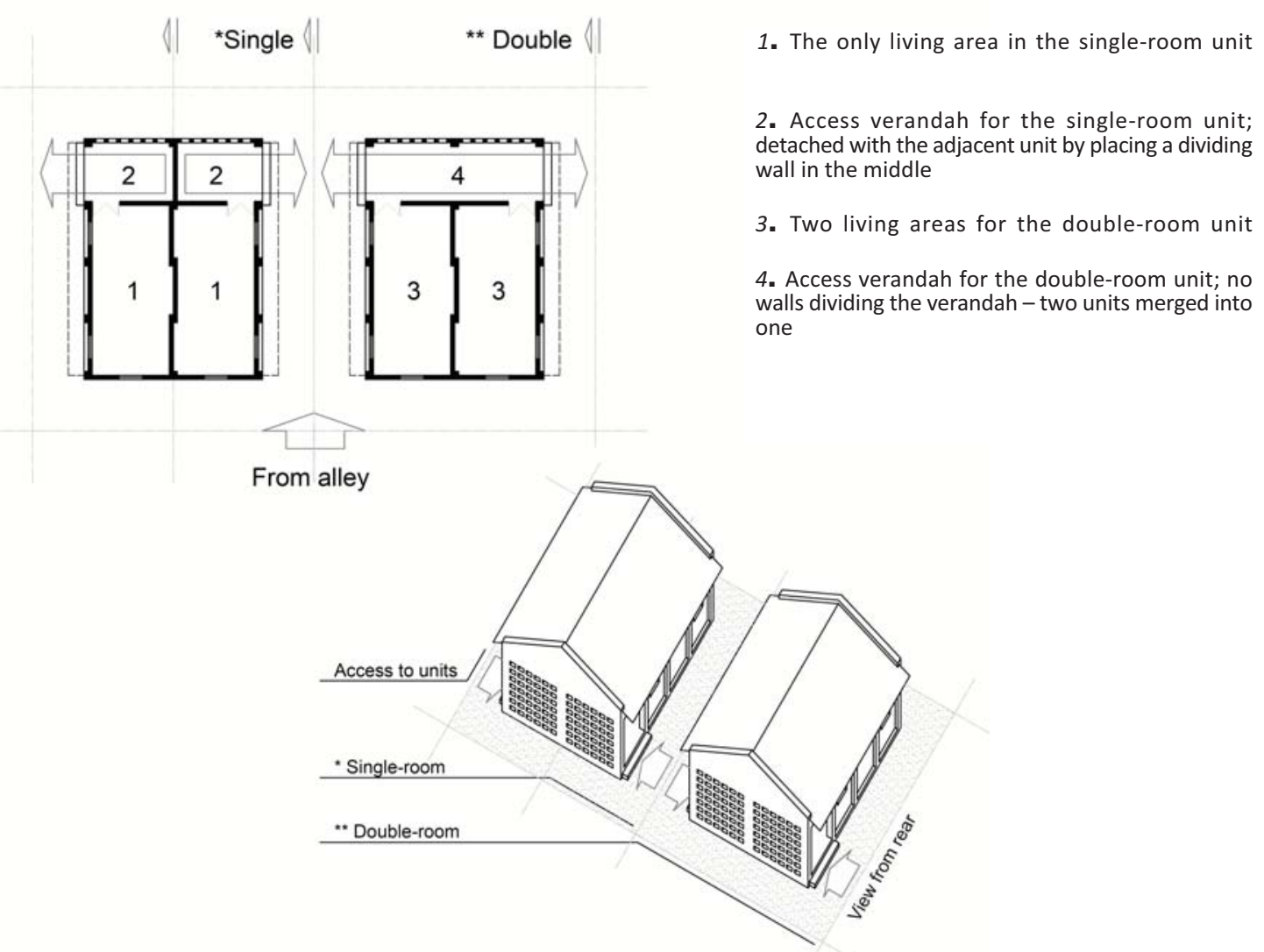

Figure-1: Vastuhara resettlement scheme - the original building provision Source: Ameen, 1987 (redrawn)

were not serviced by the government during its initial years. No electric supply was drawn in any of the sites of the Vastuhara scheme. Even the access routes (or lanes/bylanes) within the sites were left undone.

\section{METHODOLOGY, DATA AND THE STUDY AREA}

Center for Architectural Research and Development Overseas (CARDO), University of Newcastle upon Tyne in 19941995 conducted a research on transformation involving different scenarios in Egypt, Ghana, Zimbabwe and Bangladesh. Corresponding evidences from models around the global and regional initiatives of similar kind includes: a) Medinet Nasr, Cairo and Workers' City, Helwan in Egypt; b) Asawasi, Kumasi in Ghana; and c) Mbave and Highfield in Zimbabwe. Among the four case studies, the Bangladeshi scenario in Mirpur, Dhaka reveals the basic characteristic features of transformation. Based on this research, a comprehensive story on user-initiated transformation of government-built housing in developing countries has been published in 'Extending Themselves', by Dr. A. Graham Tipple (Liverpool University Press) in the year 2000.

The first two sections of this study (sections 4 and 5) are based on various secondary sources of information that interpret Vastuhara resettlement scheme from early-70s to mid-90s. These sections not only review the existing literature and project reports on the subject matter, but also address to its user-behavior tendencies in general architectural terms - an aspect that was largely ignored in the preceding studies. The fourth section (section 6) has a primary base of data and material information that have been collected with the aid of detailed and comprehensive field surveys. Among several complementary situations within the Vastuhara resettlement scheme at Mirpur, households were selected through random sampling from Section 7 alone (Figure-2). These dwelling units are representative of the whole in terms of their backgrounds in tenancy, transformative tendencies and behavioral pattern in both vertical and horizontal extents. 


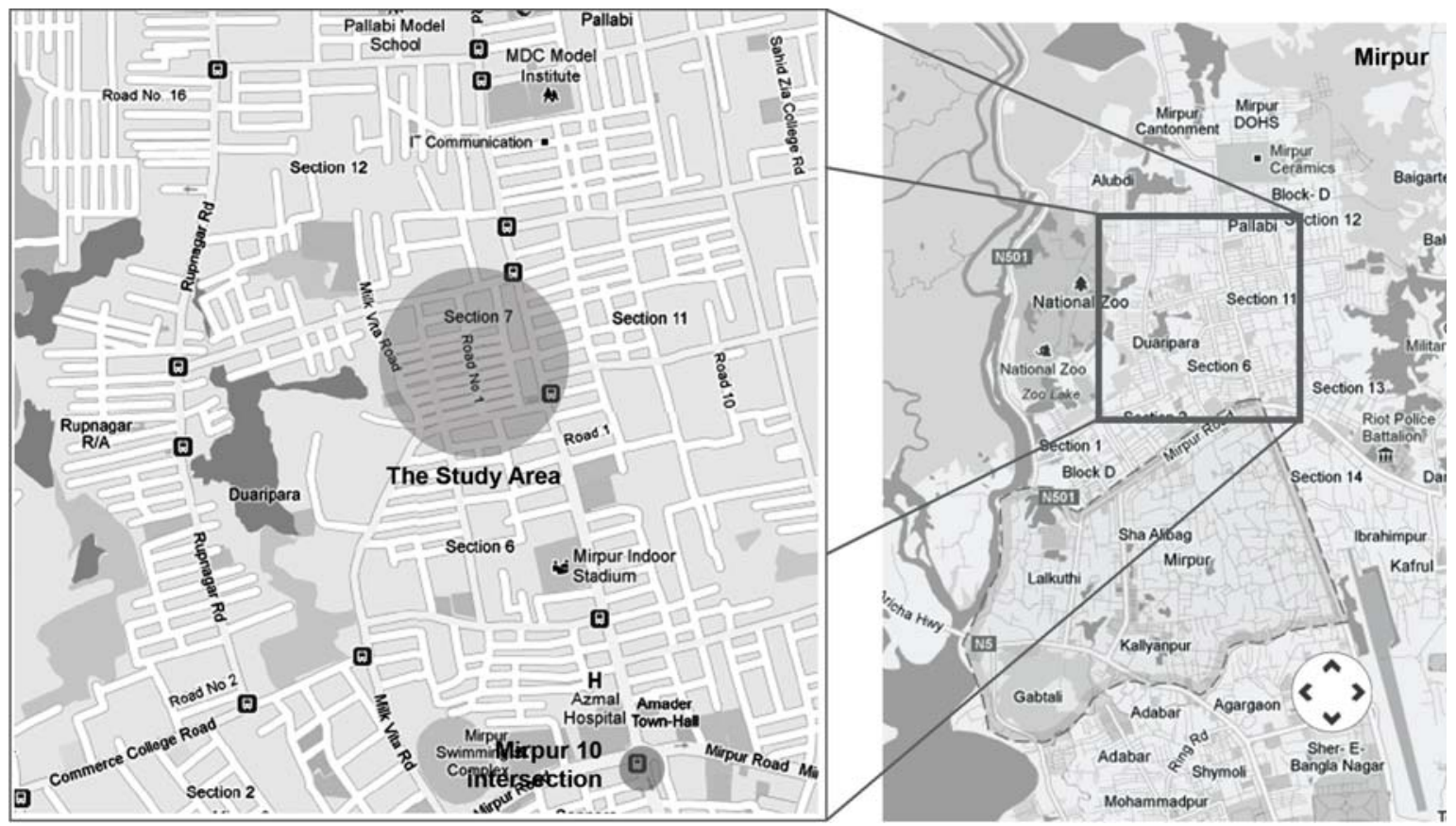

Figure-2: Early British period Map Showing Extant Mughal and Sikh period Gardens.

Data generated in the procedure have eventually resulted into a deeper insight on various causal affiliations that influence (d) its unique and distinctive nature of adaptive mechanism in the housing scheme. While the questionnaire survey was conducted, the allottees, as well as the local people, were made aware that the study would not generate any contradictory or conflicting terms with (or against) their present interest; and the sole purpose of this study was to record the details (rather than appropriating them) of the positive story regarding the transformative phenomena.

\section{TRANSFORMATION IN 'VASTUHARA' - THE BEGINNING, THROUGH ITS RUDIMENTARY STAGE}

In the late-70s, it was found that some of the unoccupied units were unscrupulously taken over by local middlemen and hoodlums (otherwise known as 'mastaan') with a view to gain some money out of a scheme that was handled badly by the authorities. ${ }^{2}$ In the process of government's failure to respond to the allotment procedure, the rest of the vacant housing units were gradually occupied by the lower-income strata of the society as well. The government agencies with the HSD, in a deferred attempt to recover its legal stance over the Vastuhara resettlement scheme, undertook the registration process of the occupiers in each housing unit (HSD, 1979). After years of negotiation, the authority eventually allowed them to stay on a rental basis. It should be noted that a survey of 251 households have confirmed that 194 were original allottees paying rents to the government, while the rest were found occupying the units on a sub-rental basis.

The phenomenal transformative development in one of the low income settlements in Dhaka was identified by (Ameen, 1987). His research establishes the basis for this section.

\subsection{Transformation in Rudimentary Form}

A rudimentary form of transformation had already begun since the construction of the dwelling units were completed in the mid-70s (Figure-3). The occupying dwellers drew illegal connections from the nearby electrical mains, installed hand-drawn water pumps (tube wells) and even made provisions for the basic sanitary systems within their sites. The HSD authorities, after the registration process was systemized, laid bricks on the access lanes and by-lanes (alleys) in conventional herring-bone pattern in an attempt

2 If this is not typical of the developing scenarios of the world, the forced intervention by the local middlemen and mastaans (usually backed by political leaders/parties) was perhaps the only reason that the HSD failed to initiate its actual program in the Vastuhara resettlement scheme. 
to revive the project. Gradually, formal supply of electricity was allowed in the project areas and so on. The initial propensity in transformative process usually took two forms:

- Alteration - extra number of rooms added through alterations of the existing scheme; changes commenced within the existing built area.

Of the 194 cases surveyed, 71 had converted their verandah spaces into additional rooms by walling up the open surfaces.

- Extension - extra number of rooms added to the original space-provisions; construction beyond the existing built area.

Among the 194 surveyed, 93 households were responsible for the construction of an extra 141 rooms - 62 by one room and 31 by more than one room afar from original provisions.

More to the discussion above, a comparison with another list of examples have revealed that among the 93 households who had extended their spatial provisions, also altered their verandahs into rooms in 55 accounts. Thus, total extra rooms for 164 families (the transformers) were 267, making an average of 1.62 rooms per household in the Vastuhara resettlement scheme.

One of the features in the original building provision that might have contributed to the occupants' initial urge to transform was the positioning of a transitory space - the access verandah - towards the farthest end of the site. The access verandah seemed to lose its actual purpose as a frontage-element in the overall functional disposition. It can be assumed that the occupants simply responded to their need for more spaces by placing vertical enclosures (temporary in nature - affordable in monetary terms) on the open surfaces and altering it into livable indoor spaces. When the benefits of alteration were realized, they proceeded on to differentiate their unit spaces by dividing it into two or more segments. The propensity for extension followed as the sites had no boundary walls or demarcation of any kind. The extent of extending their provisions on open land depended on mutual benefits of the neighboring occupants.

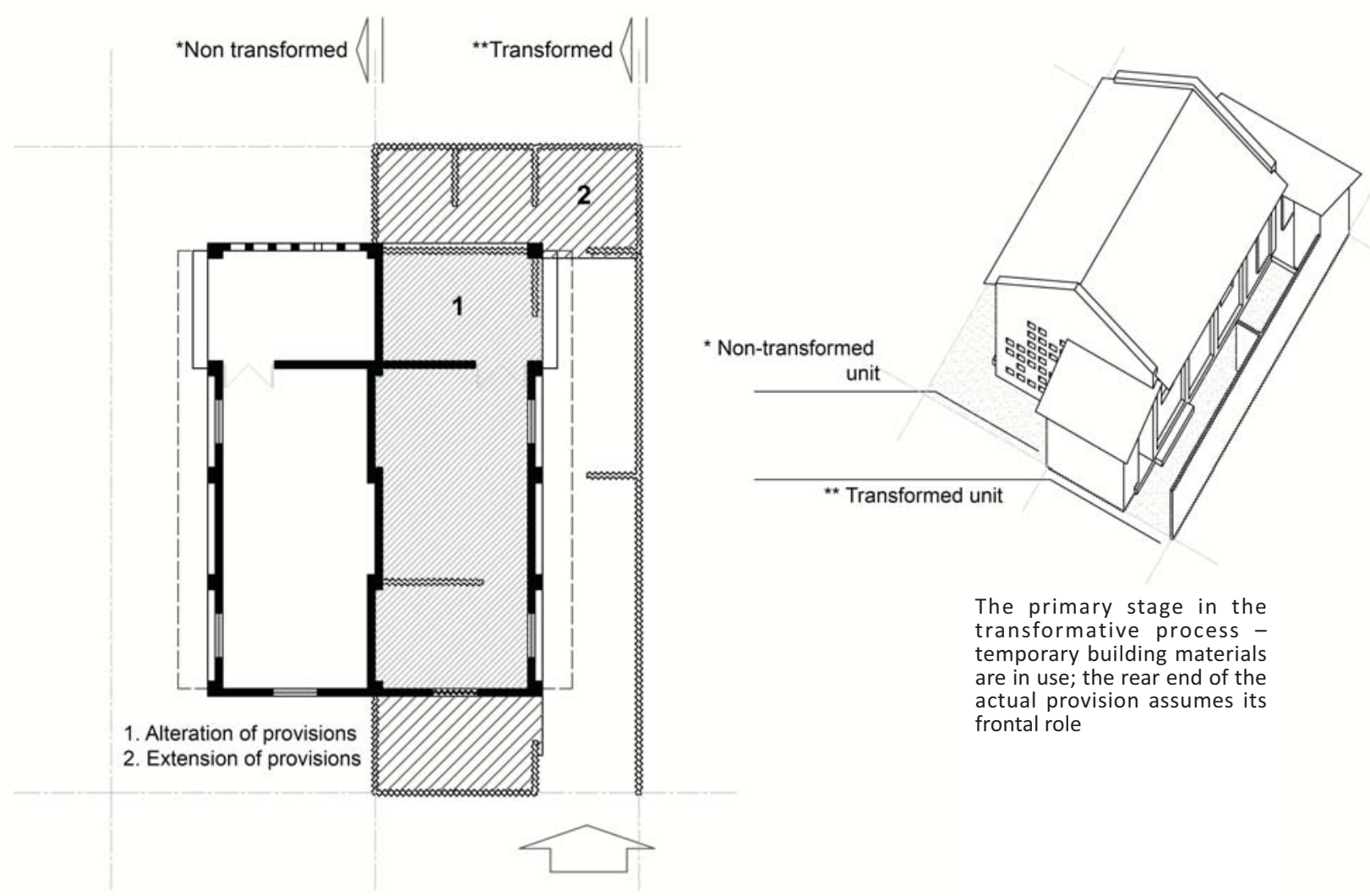

Figure-3: Transformation in rudimentary form. Source: Ameen, 1987 (redrawn) 


\section{Implications}

Although unsatisfying in quantitative terms, the Vastuhara resettlement scheme did not fail to meet the demands of its target group. Traces of proliferations by the upper income status had been found minimum. Building materials used in its earliest stage for spatial transformation were basically temporary in nature. In most of the cases $(69 \%$, approximately), it had been confirmed that families comprising of 5 to 7 members were not only extending/altering their original provisions to meet the internal demand for more spaces, ${ }^{3}$ but also subletting to others to increase their financial capacity. The realization of some specific features in the original provisions had resulted into an 'enabling' factor among its target group (Tipple, 1999).

\section{TRANSFORMATION IN 'VASTUHARA' - THE TRANSITORY, THROUGH ITS FORMATIVE STAGE}

With a marked increase in population and land value since the 1980s, accommodation in the central areas of Dhaka were becoming more and more inconvenient in terms of rapidly deteriorating supply in the overall housing stock and its economic sustenance. In the process of this, Mirpur and other peri-urban locations around the city were growing popular to the lower income stratus of the society. Some proliferations (insignificant, comparing to the total stock) had been seen in the Vastuhara housing. Considerable amount of money were paid to the registered allottees in exchange of the right to live in houses that were still under the capacity of the HSD authorities by legal means. In most cases, the newest occupants - with their weakest form of tenure actually inhabited units that had already been transformed to some extent (or more) by the original allottees. However, the occupants were generally found to be reliant on unskilled professional affiliations and the like, with their household income ranging from 58,000 to 64,000 taka (707.60 to 780.80 USD) $)^{4}$ per annum. Even the reasonably well-offs in the Vastuhara community did not belong to the higher income stratus of the society.

The ODA-CARDO affiliated investigation, led by Tipple (1994-95), provides with an in-depth study on the transformative rationales and changes that were identified in various developing scenarios across the globe, including
Bangladesh. This section renders a brief review of the research initiative while keeping the focus of this study.

\subsection{Provisioning Themselves}

Up to the mid-90s, horizontal expansion (and alteration) was the predominant form of spatial transformation in the Vastuhara resettlement scheme. While the transformative impetus of the occupants remained the same as its initial years, the forms diverged into different categories. Nevertheless, emergence of a new pattern of development had been observed where functional organization and differentiation of space-performance could assume its own identity; representing a particular economic class on its gradual upward transition (Figure-4). The transitory stage of the Vastuhara transformation can be identified in the following terms:

- Growing up to the Limit - altering and extending to their highest extents; bounded by the physical realities of their immediate surroundings, and beyond.

In almost $75 \%$ of the cases the households comprised of 5 to 7 members. Families that had commenced transformations in various development phases, actually tended to achieve some degree of favorable living conditions by providing accommodations for their own. Nonetheless, subletting extra rooms to other people in their houses seem to be a common-trend for these families with lesser economic circumstances.

Incremental growth, throughout many years of alterations and extensions, had constricted the average floor area per person and, at the same time, increased the general population density. The spaces around the dwellings were found to be entirely built up, excepting the horizontal spines left for internal circulation. Householders frequently extended their buildings up to (and over) the roadside drains to gain maximum extra space. With horizontal transformation explored and exhausted to its fullest degree, the occupants were restrained from moving upwards (vertically) by the means of tenancy rights, and regulatory and financial constraints.

- Material Permanency - using materials that are more

3 The primal need for spatial differentiation that responds to specific cultural behavior, a range of privacy settings and proxemics (see: Rapoport, 1979).

4 Conversion as in 19 July 2012.

Journal of Research in Architecture and Planning: Vol. 13, 2012 (Second Issue) - Architecture, Urban Design \& Planning 
permanent in nature; transformation from kutcha (temporary) to semi-pucca (semi-permanent). Transformers during the later development phases had begun to deploy building materials that are more durable, locally available, and in unison, easily accessible in monetary terms. Temporary partitioning walls were replaced by brick-bonded walls of (comparatively) stronger bearing capacity. The bricks were usually laid in single piles - on their sides - forming only $7.5 \mathrm{~cm}$. of thickness. The later developments ultimately took up the form of the original building provision that had a semi-permanent composition, with CI sheets topping the lower segments of pucca arrangements. The main households almost inevitably occupied the semi-pucca areas of the houses, whereas the rooms that were rented out often remained kutcha. Material permanency allowed the occupants of the Vastuhara housing to have safer and securer living conditions. Poor maintenance of building capacity is common among the entire lot, where some of the houses ( $47 \%$ of the total) had cracks on the walls and/or leaking roofs.

- Spatial Hierarchy and the Ordering of Forms disposition of spaces according to functional use and various privacy settings; a distinctive realization of form that carries identity (Figure-4).

The unit houses were originally built upon open land, without any demarcating plot boundaries. After a row of every six units (or so), the provisions for public lavatories were placed. In later periods, a tendency of developing individual plot areas had been observed the households proceeded to wall up their entire portion - up to the extensions made by the adjacent plots, and going as far as the edge of the allies. Thus, the plots usually accumulated an average width, excepting for those who had the flexibility to take up more spaces towards the end of the allies - where the lavatory facilities were left unused. The allies had been compressed to leave only 4 meters (sometimes even less) wide carriageways between the front walls of the houses.

In such condition, the narrow allies between two rows of plots were the only public accesses within the locality. A distinct enclosure of space behind the high boundary walls formed the insides of the households. Doors (usually only one on each) on these high walls adjoining the allies were the only thresholds where public spaces were succeeded by the semi-private spaces within. The household-insides were connected with the alley-outsides through semi-private transitions in the form of open corridors. These transitory spines, running through the entire length of the plots, were often partly or wholly covered with corrugated plastic sheets. The peripheral walls being solid, the corridors were the only means by which natural conditions of lighting and ventilation could reach the habitable areas. Washing and cooking areas were generally formed as parts of these transitory spines or placed nearest to them. The habitable rooms - the private domains - succeeded the semi-privates. Sometimes, more private (or inner) areas did not have the right of passage to the semi-private, but were connected to rooms that had direct admission from the transitory spines.

- Growing Commercial Needs - accommodating commercial services into the residential fabric; emergence of the new raison d'être?

Small and insignificant growth of commercial uses had been identified in the study area since its early years. By the 1990s, about $11 \%$ of the households had rooms specifically dedicated to small enterprises, manufacturing workshops and other programs that are directly related to higher income generating opportunities.

\subsection{Implications}

Although a handful, the Vastuhara households were already trending towards two-storied extensions by way of semipucca standards during the mid-90s. Growing upwards seemed inevitable for a community that was gradually improving their overall socio-economic circumstances. As per the transfer ownership documents, the authorities had enabled the allottees to extend vertically with the clause that demolition of the original building provision would have to be followed by a high-standard ( low floor area ratio.

Tipple and Ameen (1999) recommended that the requirement of building pucca stories would have to be removed, and simultaneously, planning and building codes generally applicable in the urban environment would have to be relaxed in order to prevent displacement of the poorer households to peripheral land, and spawning new slums and squatter settlements. With a view to keep the existing fabric (and potentials for growth) intact, the following recommendations were made:

- $\quad$ Adoption of permissive attitude towards the practices of transformation; in doing so, procedural delays and 

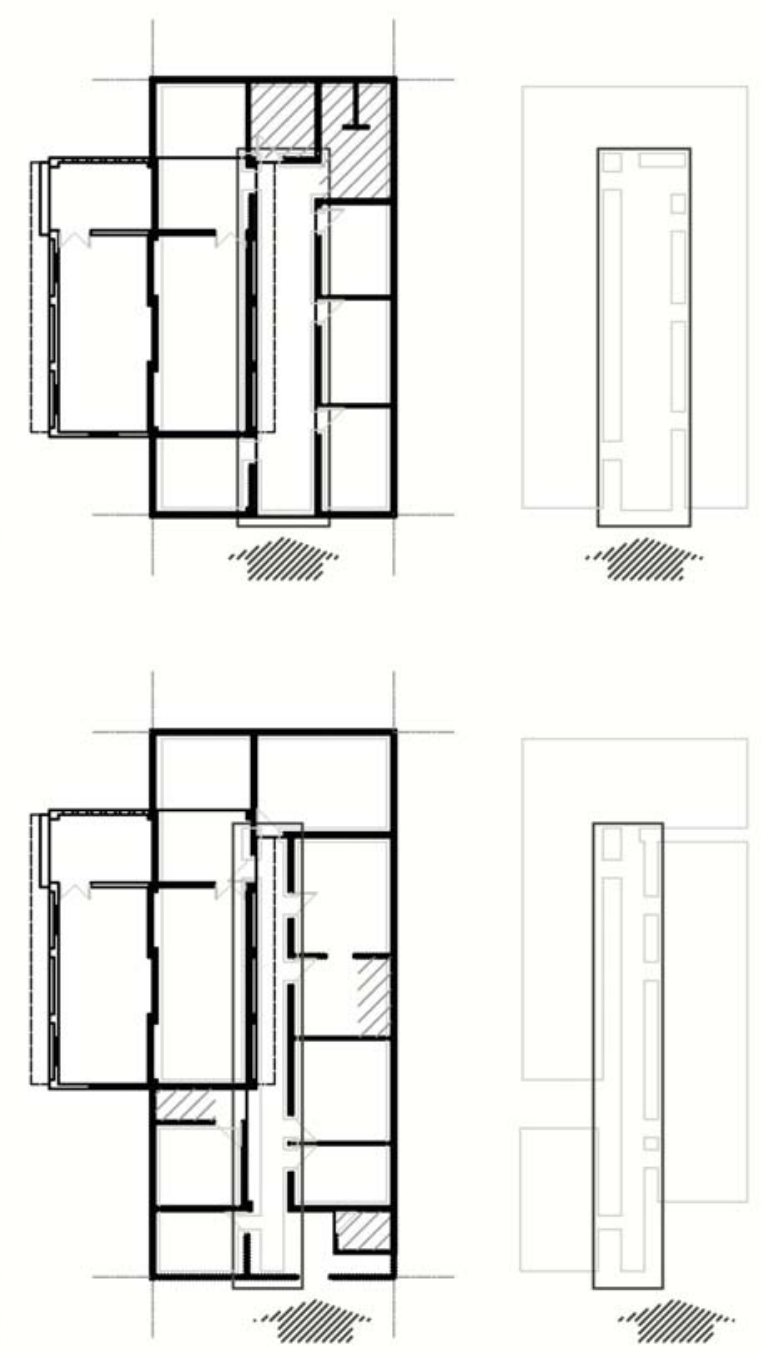

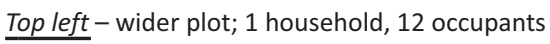

$\underline{\text { Left }}$ - wider plot, extended frontal length; 3 households, 18 occupants

Bottom - two units consolidated into one; 3 households, 20 occupants; public access into the site

The drawings in this image display the variety of situation. Noticeable is the distinctive user-behavior pattern, where the occupants tended to rely on similar hierarchical order while differentiating spaces and dealing with their privacy settings. Even the example in the bottom incorporated a transitory-inside (for the owner) that, in reality, acted as an in-site public domain (by the sublets) of the other examples.
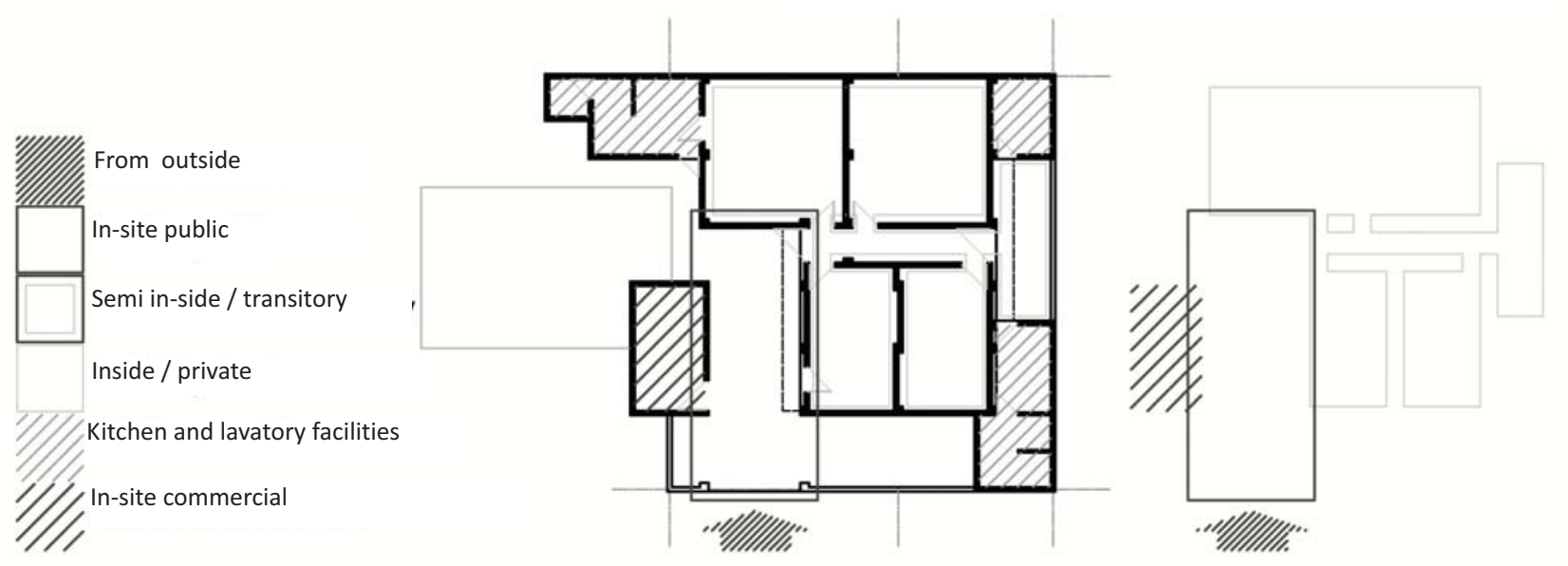

Figure-4: The transitory development-phase. Source: Tipple, 1994-95 (redrawn) 
interference would have to be kept to the minimum.

- Encouragement of local practices by allowing the semilattice; ensuring a balanced growth through a detailed development plan by incorporating flexible implementation of building code that would also take environmental issues into account.

- Enablement of financial institution into the developmentdiscourse of the poor; formulating policies that would encourage incremental growth.

- Official recognition of the urban poor and the process of user-initiated transformation in the city limits; formulating pro-poor policies within an appropriate legal framework.

\section{TRANSFORMATION IN 'VASTUHARA'-THE NEW MILLENNIA, THROUGH ITS REFORMATIVE STAGE}

Even through the late-80s and the early-90s, the formal residential areas and other housing enclaves in Dhaka had an average composition of single ownership units. With the turn of the century, this distinctive physical trait of fine grain and uniform texture has evolved into an admixture of different functional properties and multi-ownership apartment buildings containing six or more floor levels in the vertical rise. Commercial developments in these areas are the obvious brunt that grew with the rising demand of the global development-trends. In conjunction with the usual shopping complexes, the RMG industries and an array of institutional categories are the primary infiltrators that infest on the available infrastructural expediency of the organized central city areas. ${ }^{5}$

The peri-urban areas, on the other hand, offer the convenience of inexpensive labor-force for the RMG industries as the mass of low income stratus finds housing accommodations at financially accessible ranges. The Vastuhara resettlement scheme in Section 7 at Mirpur has gone through comparable circumstances during the last two decades. While legal perimeters restricted various commercial and institutional developments of larger categories from infiltrating into the study area, the housing provisions continued to grow through the means of transformative and other reformative changes that are analogous to present needs. By 2010, it has, by large, developed into a commune for the lower income groups serving the nearby RMG industries.

The study area now comprises of 30 rectilinear housing blocks placed in rigid grid-iron pattern (Figure-5). Generally, these blocks had been devised to contain (on an average) 22 plots each in closely spaced lateral arrangement, but were adjusted with the peripheral artery on their western edges. Two internal access-lanes divide the housing scheme in three columnar sections. Alleys are placed at regular intervals, intersecting these internal access-lanes in perpendicular direction and forming frontages for the individual housing units/plots. Although community facilities (e.g. schools, healthcare, social welfare, etc.) had never been planned with the original service provisions, a few NGOs were found serving the community within their appropriate ranges. A total of 1,029 plots set up the overall base for the housing scheme.

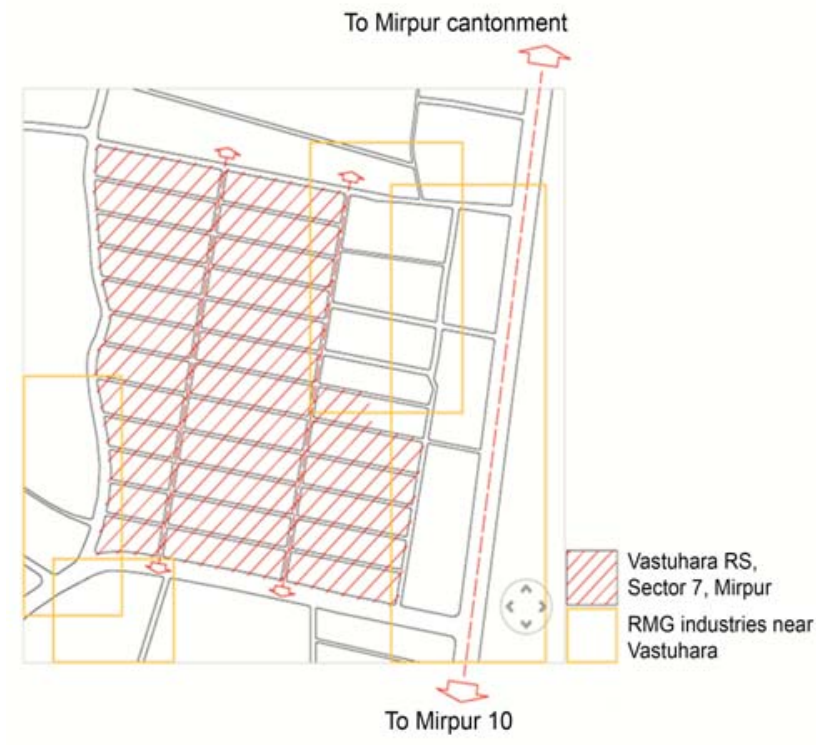

Figure-5: The study area and its immediate environs. Source: Survey, 2007-08 and 2011-12

5 According to the BBS (2010), the RMG industries in Bangladesh singlehandedly made $79.04 \%$ of the total export-oriented earnings in $2008-09$. 


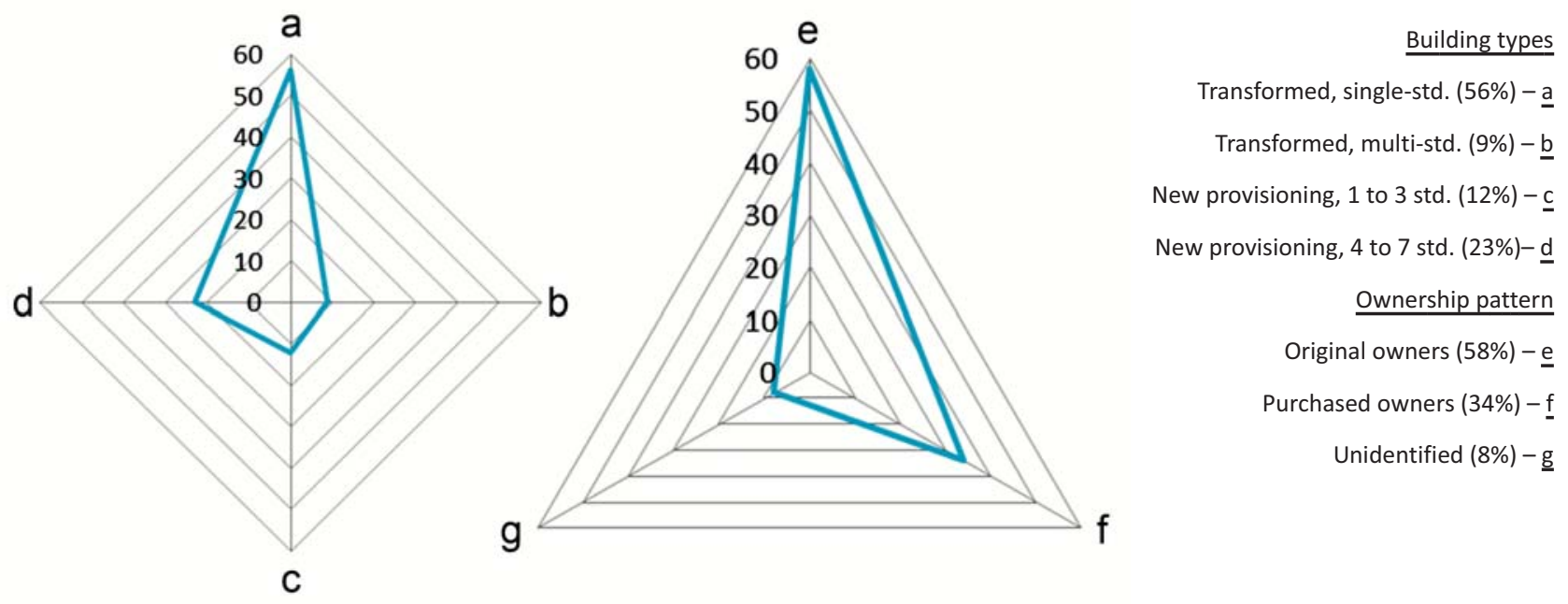

Graph-1: Distribution of ownership and building types. Source: Survey, 2011-12

At present, the Vastuhara resettlement scheme houses an assortment of development-stages that can be typologically differentiated into several groups. Transformed to both horizontal and vertical extents, the majority of the dwelling units still have the original building provisions at their cores. A good number of multi-storied developments can also be noted in the study area where the original units had been entirely erased to make room for pucca arrangements with more systematic provisioning of basic functional needs. In cases, several plots were merged together to form a larger base for comparatively taller building structures. The recent vertical rises have little to do with the original scheme, but through the process of growing up in a community with predetermined pattern and uniform texture, the growths have eventually taken a distinctive shape that are readily identifiable as its own. Moreover, these building types were found to have a direct correlation with the terms of allotment and ownership pattern for the housing scheme.

Buildings that had been transformed from their original provisions still dominate the housing scheme by $63.37 \%$, while $35.37 \%$ have constructed pucca structures demolishing their semi-pucca basics. Additionally, 1.26\% plots have been found excavated for new construction work.

\subsection{The Transformers and Their Ways of the Past}

The occupants in this group are mostly regularized tenants who had been paying rental fees to the authority since the earliest years. Transformations of various stages - from $k u t c h a$ to semi-pucca, including extension of additional rooms - took years for these initial settlers to avail. In comparison with the transformed single-storied buildings, the multi-storied versions are in short supply also because their structural members at the ground levels usually do not have the capacity to bear additional floor level on top of them. Nevertheless, buildings extended up to three levels have been recorded.

It has been identified that $9.04 \%$ of the plots in the housing scheme and $38.55 \%$ among the transformed households have converted their rooms into small community shops. Mostly, these shops take up the frontages or corner positions from the accommodating households. The households on the intersecting alleys seldom convert their entire extended street-side segments into such commercial enterprises. In recent years, the corner plots were extended further into the lanes; encroaching over the drainage systems by means of $k u t c h a$ construction materials. On the arterial accesses to the housing, similar conditions were seen to be adapted for workshops or appropriate provisions that serve the greater peripheral outside.

- Transformed, Single-storied - generated through alterations and extensions of the basic housing unit; building activity limited to the ground level (Figure-6).

Through the last two decades, plan-arrangements in the transformed single-storied houses for both land provisions remained the same. A few design considerations were identified that had been adapted by the community in general as supplementary advancements. In the form of problem-solving realizations, these details have added merit to the 


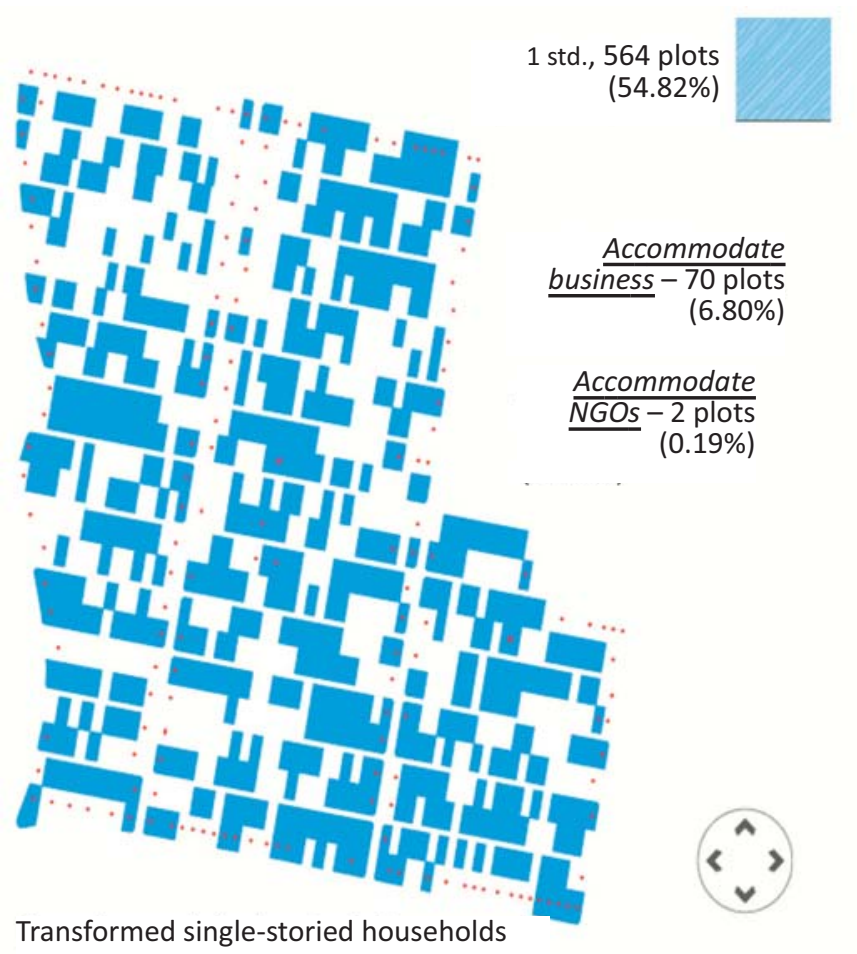

Figure-6: Ground area coverage by the transformed households. Source: Survey, 2011-12

archetypal image (and functioning) of the Vastuhara resettlement scheme. Manually operable wind-scoops with the CI roofing for natural lighting and ventilation, and appropriating the use of rainwater ducts and spouts are the distinctive features that have been achieved through simple vernacular means. Apart from all these, a tendency for putting up their frontal façades with vertical brick-bonded stretches and rendering the outer surfaces with local motifs display the residents' urge for individual social identity within a mass housing scenario.

- Transformed, Multi-storied - availing transformative changes in multiple floor levels; building activity extending upwards.

In $1.65 \%$ units, partial or minimal transformation propensity in multiple floor levels has been observed. Above their general ground level constructions, mere provisions for a couple of extra rooms had been created with the means of kutcha building materials. In such cases, single-flight ladders (made of GI pipes and/or flat iron bars) are placed within the base-level transitory spaces to access the first floor extensions. Usually, these semi-private transitions remain open to sky through

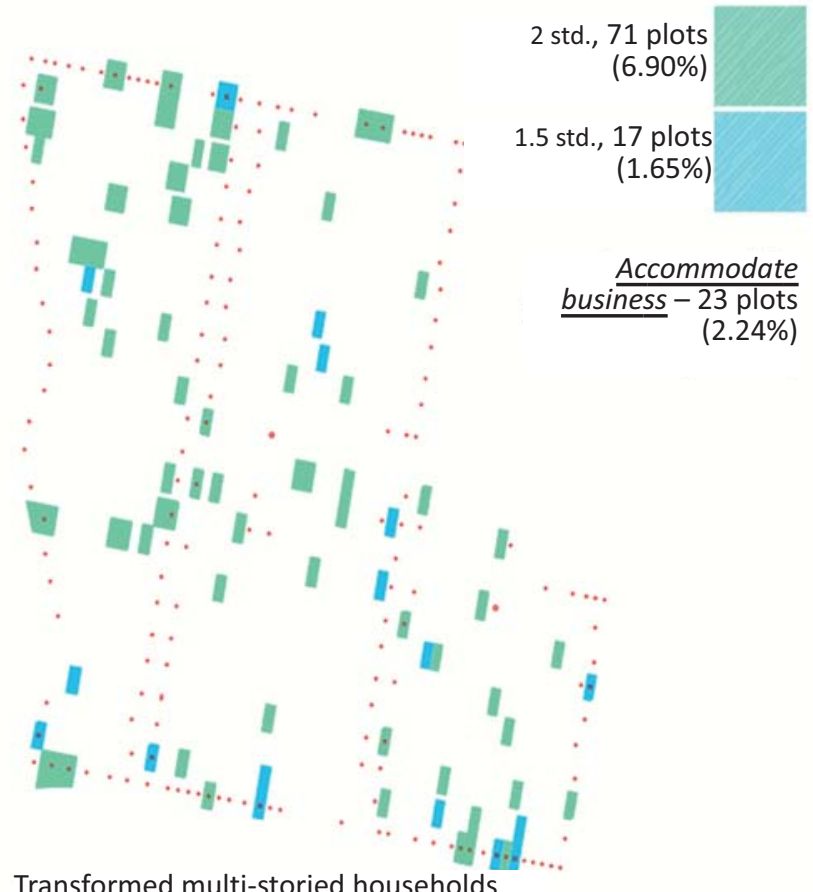

Transformed multi-storied households

both the levels (Figure-7). No partially transformed multi-storied unit was found exceeding two successive floors. Characteristically, transformers of this variety are those who have larger household size with more years of experience in such trade.

The other category belongs to the households who are basically the absentee allotment holders and/or investors paying one-off financial packages to the first parties; with a sole intention of extracting utmost financial benefit from the housing scheme that required no significant form of investment. In such cases, a rectangular form of an additional floor takes up the entire area the plot at the first floor level, exclusively covering the general ground level provisions and thus converting the archetypal transitory space into an internal passageway (Figure-7). The upper level floors in these situations are often seen extending beyond their ground floor frontage limits and making intrusions over the narrow alleyways. Three storied transformations of the similar kind are comparatively rare, but increasingly gaining popularity among the Vastuhara settlers as this particular type meet the demand of the low(est) income workers with the RMG industries in terms of their affordability and sustenance paradox. A good number 
Partially transformed multi-storied

Top right - an open-to-sky transitory space in both floor levels; better natural conditions in wider plots

Left - an open-to-sky transitory space in both floor levels; upper floor extension exceeds plot limit beyond its façade frontage

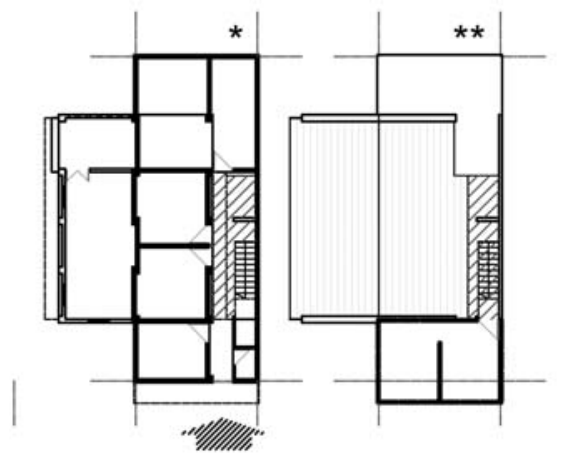

* Ground Floor

** First Floor

Enclosed transitory with natural light

Enclosed transitory without natural light

Open-to-sky transitory
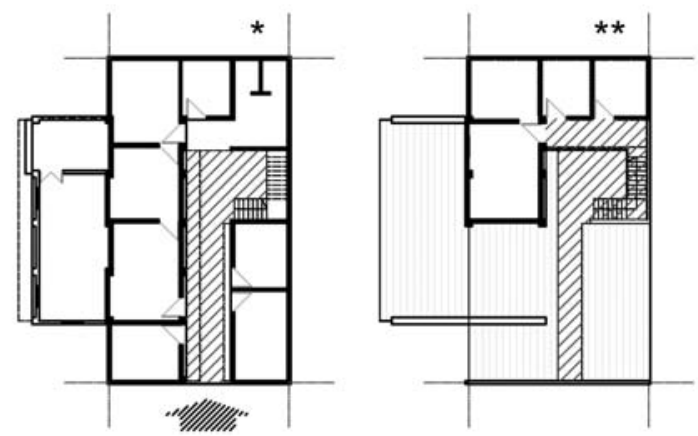

Fully transformed multi-storied Bottom right - the transitory space turns into an internal corridor, and the successive passageway in the upper level has a skylight throughout its entire length
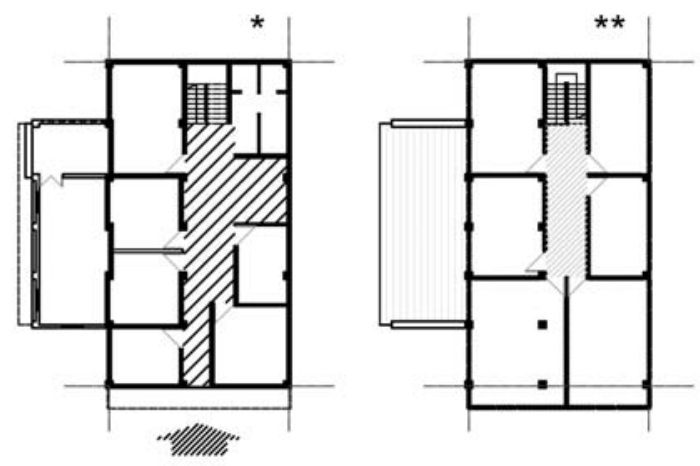

Figure-7: Transformed multi-storied households. Source: Survey, 2007-08 and 2011-12

of the original allottees and the advanced developers (see the following subsections) have expressed their dissatisfaction that transformations such as this would eventually turn the housing scheme into a typical squatter settlement.

\subsection{The New Builders and the Present Duality}

Comparing to the previous category of transformed singlestoried households, newly (recently) constructed building provisions in the Vastuhara resettlement scheme is reasonably in short supply. The households are basically the higher income group proliferators who had procured the use of these plots by paying one-off packages to the original allottees with lesser economic means. Essentially, the purchased allottees seem to have been accessing various formal and informal financial organizations for the development of their respective properties. A corresponding group of government class III and IV employees, who were originally allotted with the Vastuhara plots, also fit into this particular category. An indistinctive differentiation can be made from the above discussion that newly constructed buildings comprising of more than four floor levels belong to the purchased tenants, while constructions below this vertical extent ( 1 to 3 storied pucca formations) are to the originally allotted households with secured but insignificant income structure (Figure-8).

For the recent multi-storied constructions, small community shops are conventionally placed in distinctive detached arrangements with/against their original pucca building provisions (Figure-9). Whereas, transformations of semi-pucca arrangements incorporate these additional commercial chambers along their sideways as extensions from their core structure. Permanent multi-storied buildings seldom accommodate similar functional arrangements in their ground floor levels.

- New Provisioning, Multi-storied - pulling down the entire transformed accumulations, including their original building provisions in order to create new structural and functional arrangements; permanent constructions of multiple floor levels. 


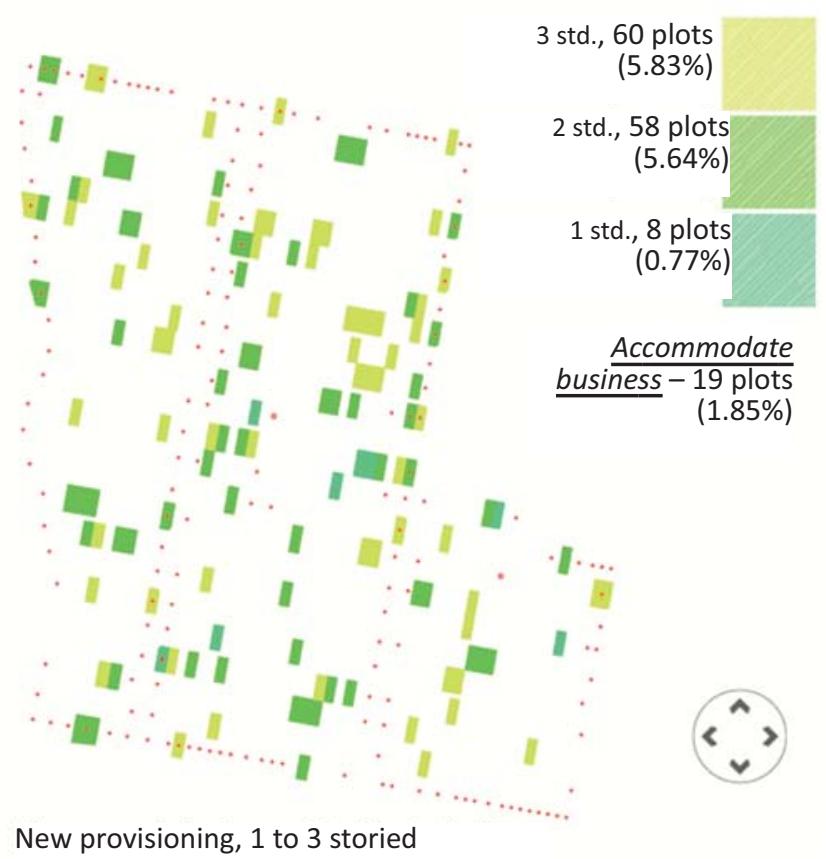

Figure-8: Ground area coverage through new provisioning. Source: Survey, 2011-12

The recent developer households are generally slow builders who take their time to accumulate the money required for each segmental or partial construction phase. In this process, an average six storied pucca building takes 10 to 15 years (sometimes even more) to be completed by the particular user group. Safety standards and rules of clearance with adjacent plots are frequently violated as the entire unit areas are built up in an attempt to extract the utmost from their respective land provisions - a tendency that had been evident with the original transformation practices in the Vastuhara housing scheme. Arranged in closely spaced grids (conventionally, in post-lintel structural system), the buildings are often trapped within neighboring multirises on the three sides, leaving only the front surface for admittance of natural conditions (Figure-9). Indents on the side façades are seen, but this treatment has been proven inadequate as the sun does not reach the bottom levels. These households generally occupy multiple floor levels, renting out the remaining spaces to persons who can avail paying charges higher than that in the transformed categories.

\subsection{Comparative Discourse}

The growing distance in housing divide between the two broad-based categories has resulted into dissatisfaction and

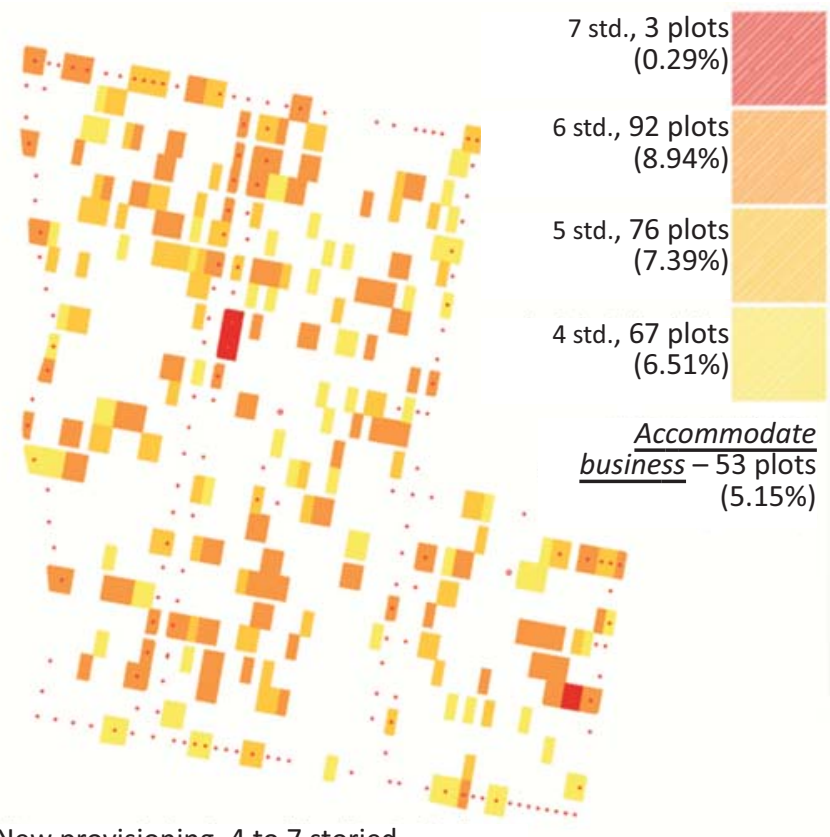

New provisioning, 4 to 7 storied

discontentment among the Vastuhara settlers. Comparatively disadvantaged - the experienced transformers with lesser economic means; the superlative majority - are constantly blaming the newer developer households of obliterating the existing neighborhood fabric by creating overcrowding situations and undesired growth. Whereas, the other group - the parties who were able to access more permanent means of living - are (rightfully, of course) continually looking forward to greater objectives of social and economic progression by defying the realities of the past.

In the present circumstances, it can be argued that the housing conditions in Vastuhara resettlement scheme is far improved than any other low income settlement in the city. The settlers have not only increased the total housing stock of the community, but also improved their economic capacity by adapting transformative mechanism to their original building provisions. The entire settlement, up until now, has grown to this extent without putting any (additional) pressure on government resources.

\section{CONCLUSIONS AND RECOMMENDATIONS}

Although the study shows that the concept of transformation has made efficient use of existing finite resources particularly serviced land, infrastructure, building materials, etc.; no initiative has successfully been taken to demonstrate 
Top right - a corner plot at an arterial access-lane; semi-pucca community shops are attached against its ground floor arrangements; adequate natural condition as the multi-rise is open on two surfaces

Left - a multi-rise trapped from three sides; the building can only be ventilated from its front façade; worst natural condition
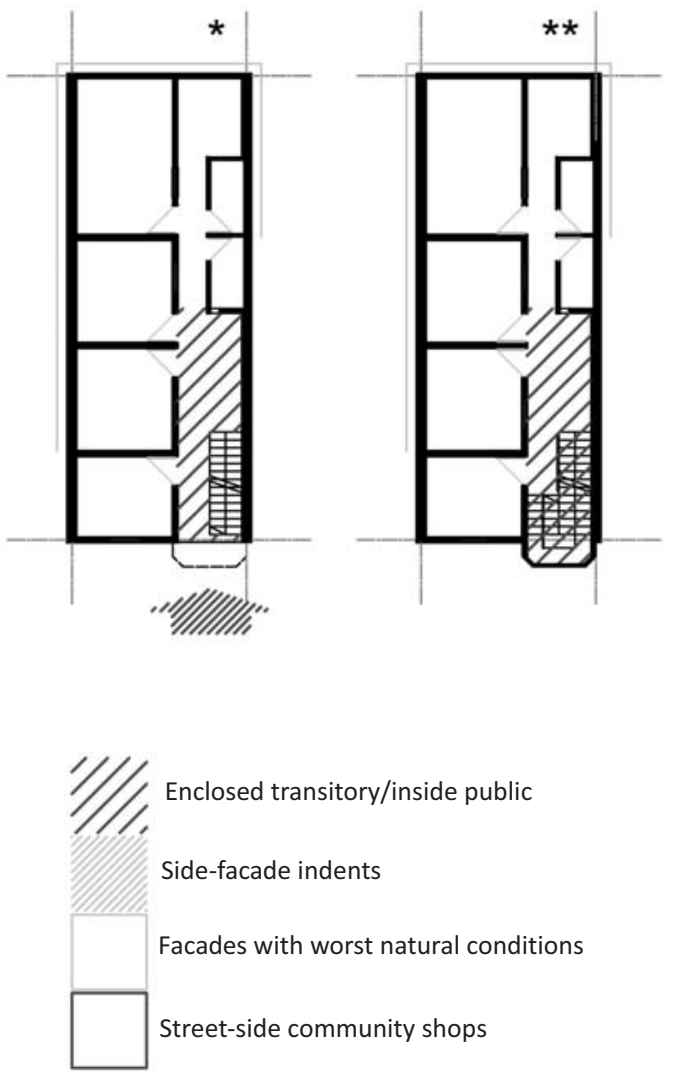

Enclosed transitory/inside public

Side-facade indents

Facades with worst natural conditions

Street-side community shops

Figure-9: Multi-storied households - the new provisioning Source: Survey, 2007-08 and 2011-12

the result of the concept. The absence of which has ensued in the ignorance of the outcome in the long run. At this stage, it has become difficult to ascertain whether the resettlement scheme had been actually addressing to the needs of its original target group or not. But the story of Vastuhara housing through the last 30 years or more have been proven to be a constructive one. The authorities concerned have a lot to learn from its mistakes and also from its favorable outcomes that had eventually contributed to the sustenance of a low income community.
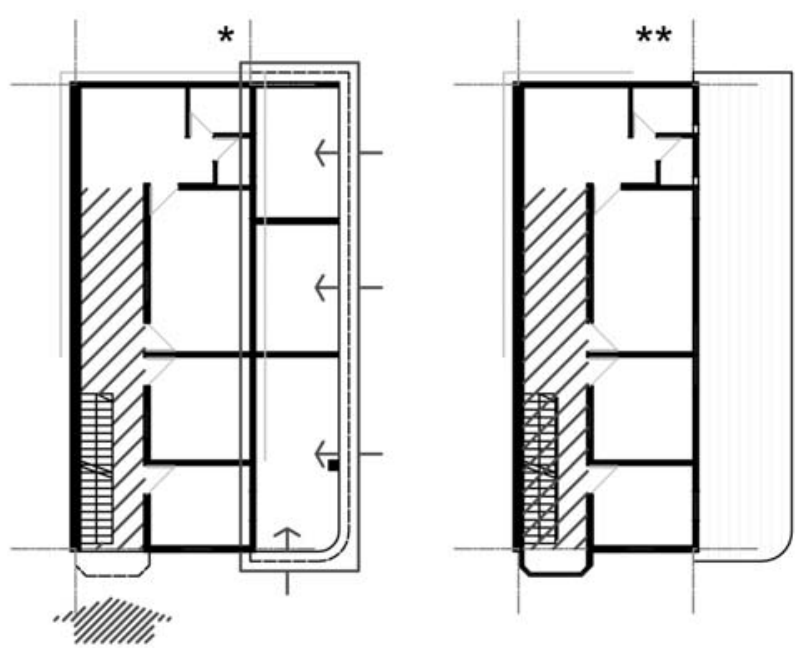

Bottom - two plots merged into one; a multirise trapped from three sides; inadequate natural conditions; indent on a side-façade only act as an exhaust duct for the kitchen

In almost all the cases, each floor in a multirise situation (with new structure) acts as an individual transformed single-storied household. Unlike their predecessor(s), these floors are the worst examples for inadequate sunlight and ventilation. Like its earlier development-phase (section 5), the privacy settings in the semi-inside/transitory spaces are grossly juxtaposed with various insite/inside public accessibility ranges.

\section{* Ground floor}

** Typical floor

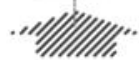


For the transformed categories, suggestions can be made with respect to the components or functional devises in the form of various privacy situations. These devices had been identified in the households' existing alteration and extension practices and the majority of the tenants, still in their transformative process, are contingent to these features as the basic physical manifestation of user-behavior settings. Ideal compositional variations among the components in terms of their functional and environmental values can be conveyed among the target group so that they can 'do the same thing' but somewhat in a better and acceptable way. In doing so, localized building trends and space-standards should be encouraged instead of their globalized and/or modernized equivalents.

The process of transformation conventionally involves semipucca construction methods that supports flexibility of horizontal growth and convenience in future alterations, but at the same time, restricts its occupants from growing upwards. Vertical extension up to two floor levels should be encouraged, where the transitory (semi-private) component is repeated in both the floors. Semi-pucca buildings exceeding this ceiling are extremely risky. The settlers in the housing scheme should be warned of the consequential threats such development has to offer. Buildings above two floor levels should be of pucca standard. Height restrictions for the area must follow the limits applicable for the particular city district (i.e. Mirpur). More to this, new provisioning having multi-storied structural capacity should obligatorily comply with bylaws that are more responsive to the housing scheme.

The study area has been found to be a gross distribution of plots having no significant concern for spatial hierarchy or interactive social provisions. Adequate community facilities/services could have commenced moral advancement for the community. With respect to the character of the district, provisions for commercial enterprises could have created employment and/or investment opportunities for the economically disadvantaged residents. Nevertheless, in the present circumstances, small-scaled commercial developments within individual plot-boundaries should be promoted; given that the allottees will be entrepreneurs or (at least) partners in business.

If the government is convinced that the Vastuhara resettlement scheme should keep in track with its general objective (i.e. providing home for the shelterless), proliferating tendencies of the higher income groups should be stopped by any means possible. It should be strictly maintained that the allottees do not profit from selling out their provisions to anyone other than surrendering their leases to the authority.

For each scheme, self-compliant advisory bodies should be assembled who will act as guides to the overall development process, and facilitate the use of necessary logistics and finance that are appropriate to the households' income structure. The advisory bodies should comprise of architects, planners, economists and experts in social welfare. Unconstrained involvement of various NGOs and complementary organizations in the development sector should also be encouraged. Most importantly, participation of the households in the development process must be ensured if an all-encompassing and practicable outcome is to be expected.

\section{Acknowledgment}

The author is indebted to the significant input of

Dr. A. Graham Tipple

United Nations consultant

Housing and Urban Issues in Rapidly Developing Countries

\& Former faculty member; director, CARDO

School of Architecture, Planning and Landscape

University of Newcastle upon Tyne

United Kingdom 

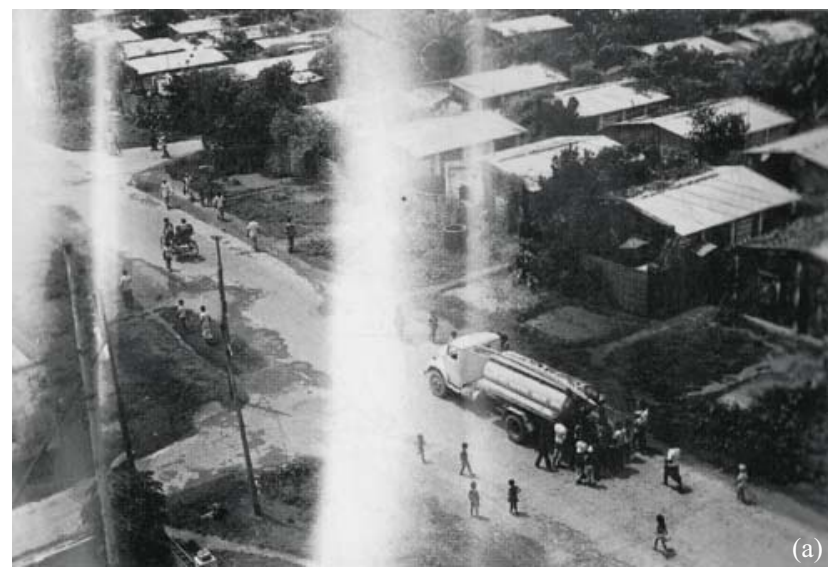

Decade 1975-1985

a. Aerial view of the resettlement scheme - the original provisions.

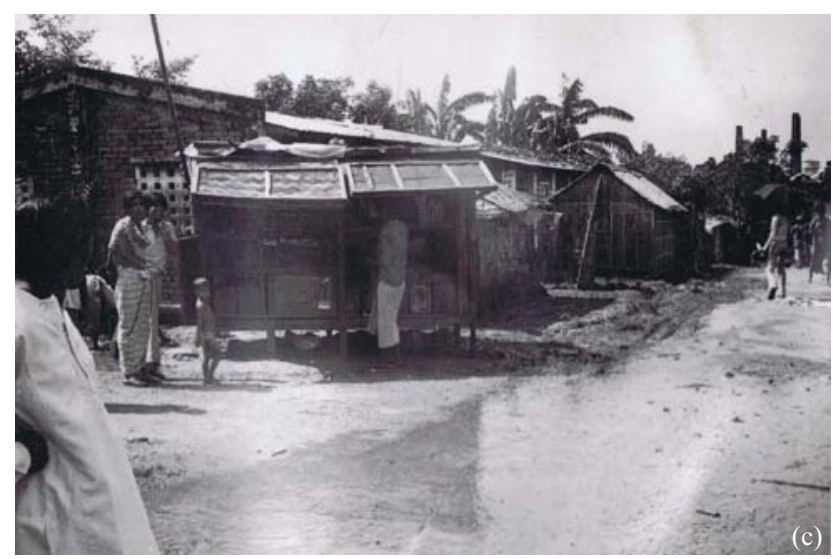

c. Transformation in rudimentary form; the frontal commercial impetus.

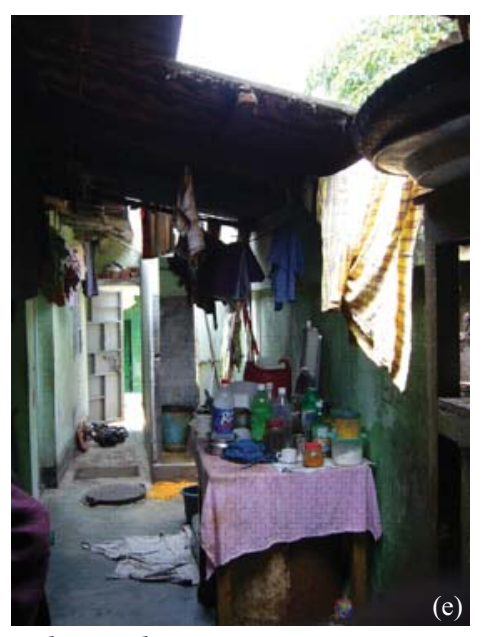

Decade 1995-2005, and onward

e. A semi-open transitory spine; commonly treated in transformed singlestoried category to allow natural lighting and ventilation.

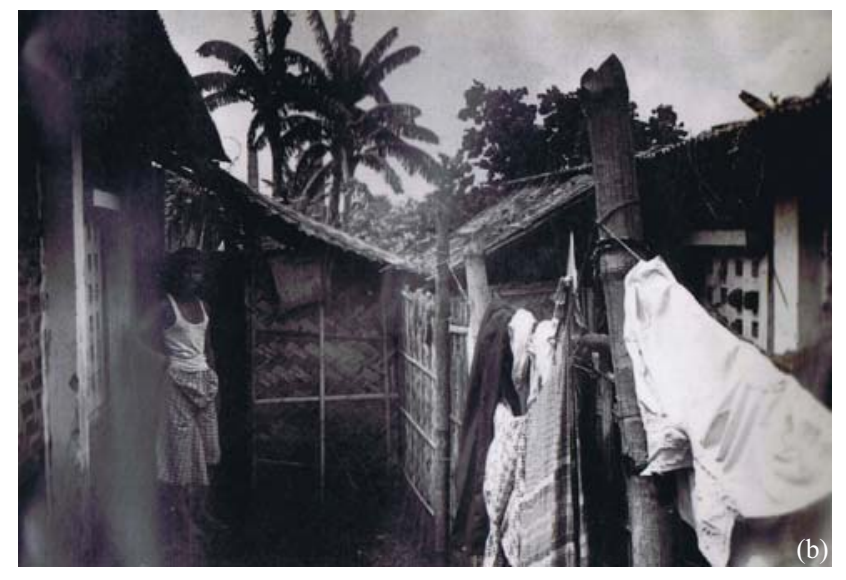

b. Transformation in rudimentary form; kutcha partition wall between two detached housing units.

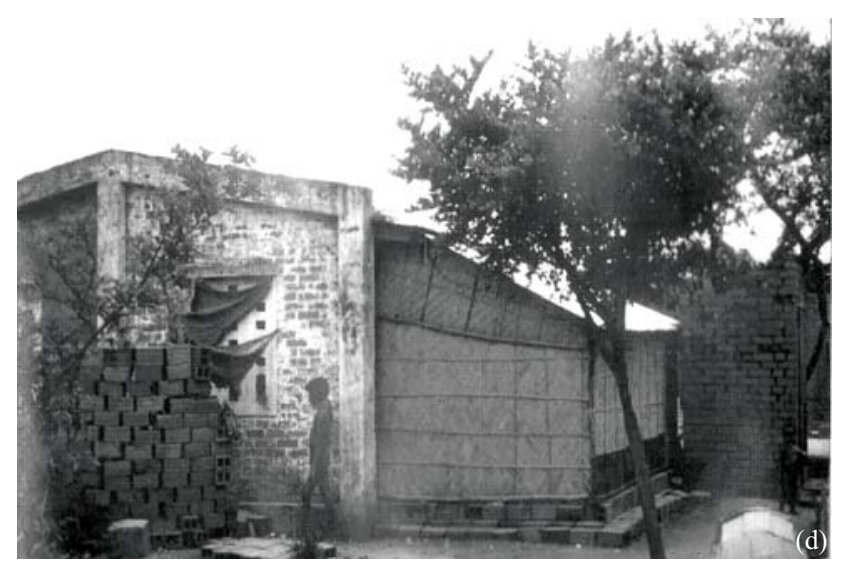

Decade 1985-1995

$\mathrm{d}$. The formative stage; the original housing unit extended by means of both kutcha and pucca provisions façades.

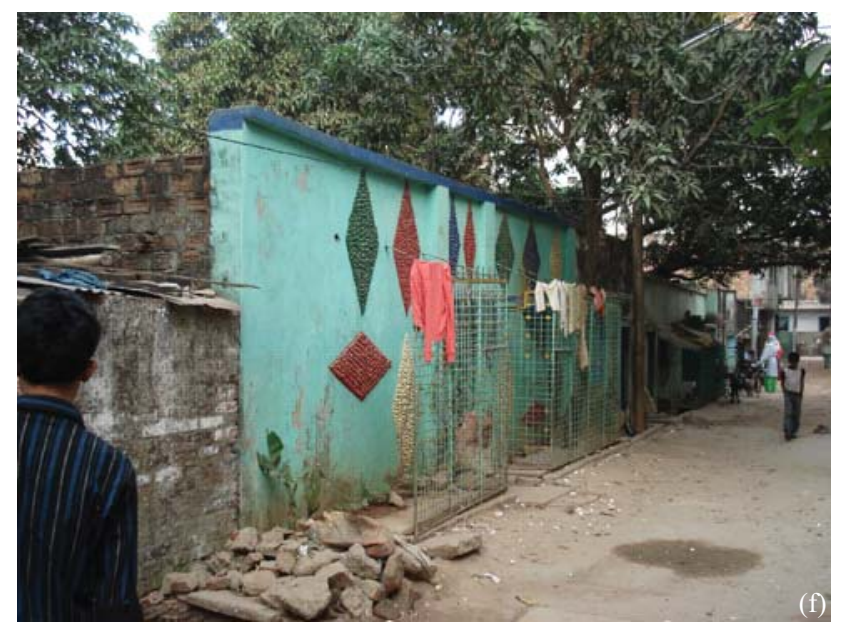

f. Transformed single storied households; frontal façades are detailed and differentiated from the adjacent units - an expression of individual social identity; the core provisions are still inside. 


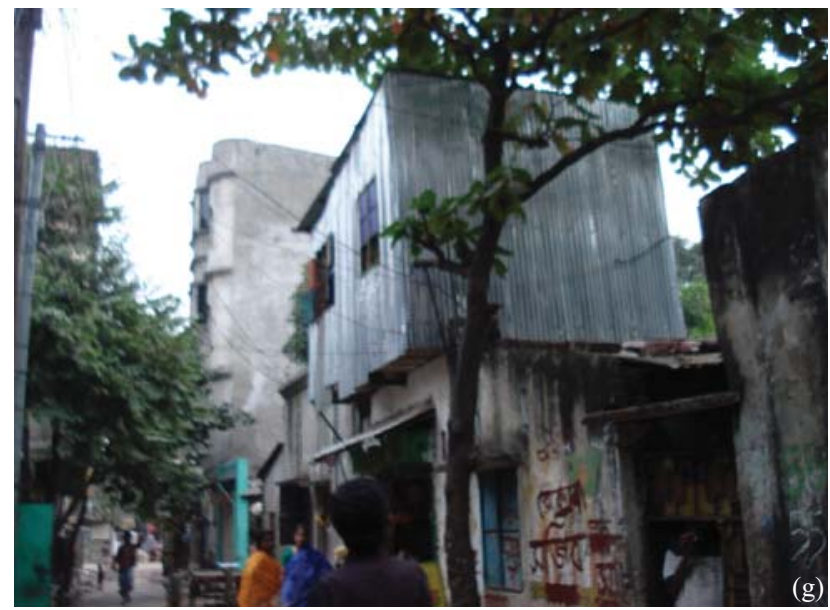

g. A partially transformed multi-storied household; vertically extended by means of kutcha building materials.

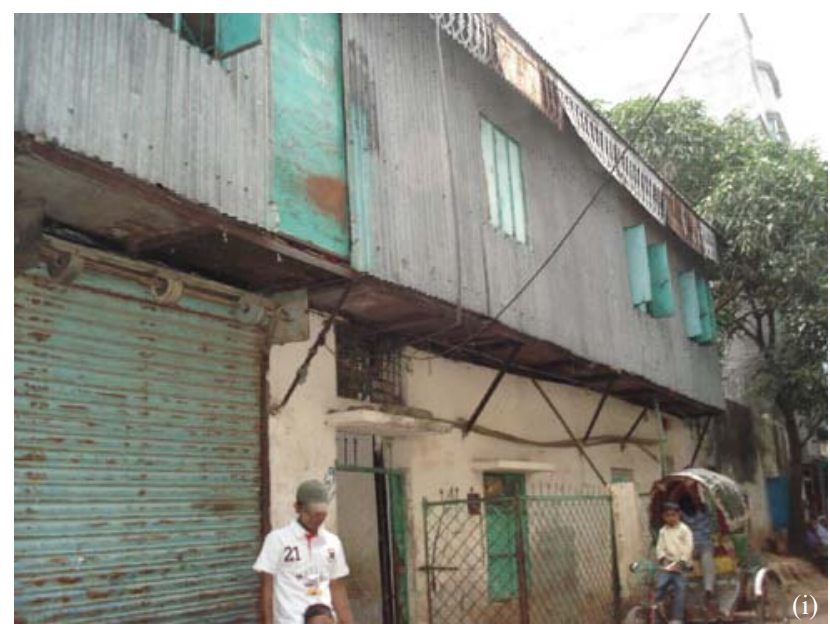

i. A fully transformed multi-storied kutcha household.

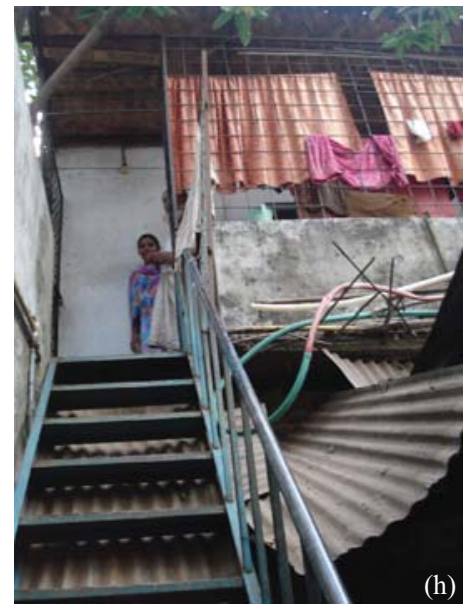

h. A partially transformed multi-storied household; the access ladder to the upper level.

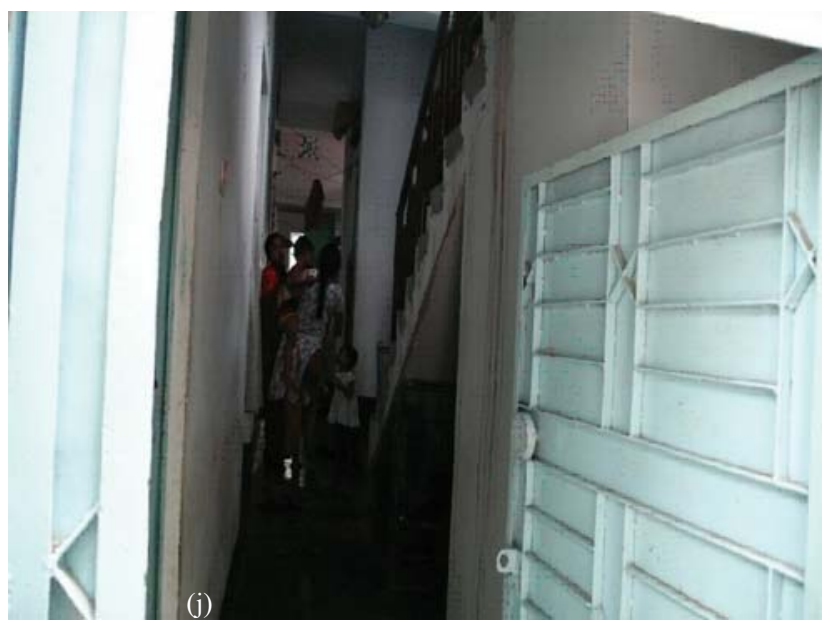

j. A newly constructed multi-rise; an open stairway visible on the right; semi-inside turns into an inside public dominion.

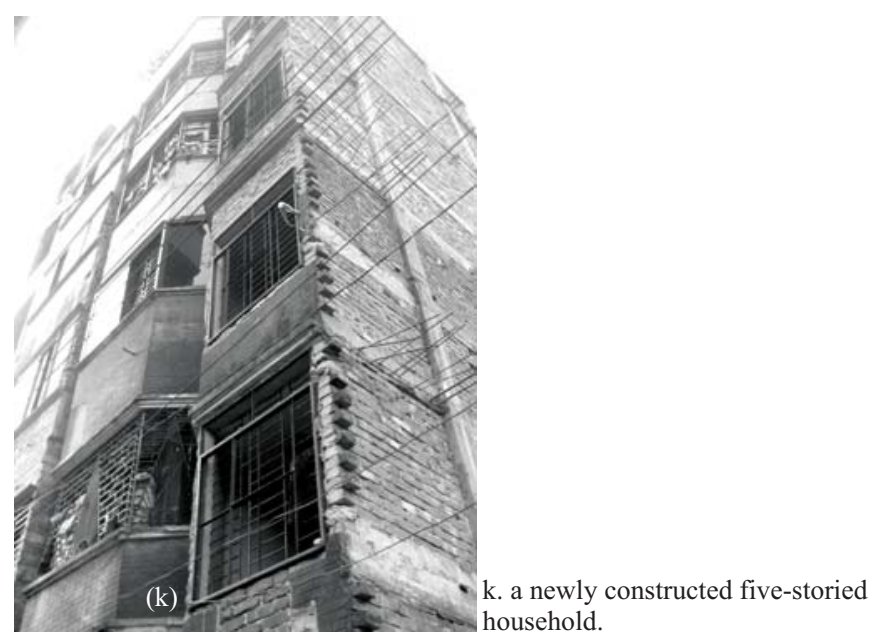

Figure-10 (a-k): 'Vastuhara', through decades.

Source: HSD, 1979; Ameen, 1987; Survey, 2007-08 


\section{References}

ADB-GoB, 1993; Housing Sector Institutional Strengthening Project (final report); Asian Development Bank and Government of Bangladesh; Dhaka.

ADB-GoB-LGED, 1996; Urban Poverty Reduction Project (draft: final report); Asian Development Bank, Government of Bangladesh and Local Government Engineering Department; Dhaka.

Ameen M.S., 1987; Housing for the Lower Income People of Dhaka, Bangladesh: A peri-Urban Development Approach (unpublished Ph.D. dissertation); University of Newcastle upon Tyne, Newcastle.

Ameen M.S., 1992; “Transformation Practice in Low Income Housing”; Conference Proceeding: 18th WEDC Conference

- Water, Environment and Management; Kathmandu.

Banks N., 2008; “A Tale of Two Wards: Political Participation and the Urban Poor in Dhaka City”; Environment and Urbanism, Vol. 20(2); International Institute for Environment and Development (IIED).

Beyer G.H, 1965; Housing and Society; Collier-Macmillan Ltd.; London.

Elahi K.T., 2005; "Understanding the Sustainability of Dhaka City: Some Preliminary Observations"; Bangladesh National Geographical Association, Vol. 33, Nos. 1\&2; Bangladesh National Geographical Association (BNGA); Dhaka.

HSD, 1979; Vastuhara Resettlement Scheme; Housing and Settlement Directorate; Dhaka.

Islam N. (ed.), 1996; Dhaka - from City to Megacity; Bangladesh Urban Studies Series No. 1, Urban Studies Programme, Department of Geography, University of Dhaka; Dhaka.

Islam N., 1998; “Dhaka City: Some General Concerns"; Conference Proceeding: Reforming Dhaka City Management, in: Asian Cities in the 21st Century: Contemporary Approaches to Municipal Management; Asian Development Bank (ADB).

Islam N., 2005; Dhaka Now - Contemporary Urban Development; Bangladesh Geographical Society (BGS); Dhaka.

NHA, 1993; National Housing Policy, 1993; Ministry of Housing and Public Works, National Housing Authority; Government of Bangladesh.

NHA, 2004; National Housing Policy, 2004 (amended); Ministry of Housing and Public Works, National Housing Authority; Government of Bangladesh.

NHA, 2010; National Housing Policy, 2010 (amended); Ministry of Housing and Public Works, National Housing Authority; Government of Bangladesh.

Rahman G., 2008; Town Planning and the Political Culture of Planning in Bangladesh; Dhaka.

Rapoport A., 1979; "Cultural Origins of Architecture"; Introduction to Architecture, Snyder J.C. and Catanese A.J. (eds.); NY.

Tipple A.G., 1994-95; "Extending Themselves - Resident Transformation of Government-Built Housing in Developing Countries"; Draft final report on ODA research scheme, CARDO; University of Newcastle upon Tyne; London.

Tipple A.G., 1999; “Transforming Government-Built Housing: Lessons from Developing Countries"; Journal of Urban Technology, Vol. 6, No. 3; The Society of Urban Technology; London.

Tipple A.G. and Ameen M.S., 1999; “User Initiated Extension Activity in Bangladesh: 'Building Slums' or Area Improvement?”; Environment and Urbanization, Vol. 11, No. 1.

UNDP-UNCHS, 1993; Bangladesh Urban and Shelter Sector Review; United Nations Development Program and United Nations Center for Human Settlements; Dhaka. 